\title{
Os mediadores do patrimônio imaterial
}

\author{
Lucieni de Menezes Simão*
}

\begin{abstract}
R esumo: Este artigo propõe uma reflexão quanto aos limites dbs atuais instrumentos de salvaguarda e preservação do patrimônio imaterial. Orientados pelas reflexões da antropologia, levantamos questões relativas aos direitos autorais coletivos e ao retomo dos benefícios dbtidos pelo registro do patrimônio imaterial. A devolução dbs resultadbs também implica uma questão discursiva. Portanto, vamos comparar duas experiências institucionais: a primeira, proposta pelo Museu do Índio, sobre o registro da pintura conporal dos índios W ajäpi do Amapá. A segunda, sobre o projeto Celebraçães e Saberes da Cultura Popular, do Centro Nacional de Folclore e Cultura Popular. Seguem-se daí as indagaçães sobre as maneiras de se aperfeiçoar os mecanismos de registro e demais políticas públicas de salvaguarda.
\end{abstract}

Palavras-chave: patrimônio imaterial, inventário e registro, antropologia.

\section{Introdução}

$\mathrm{Na} 24^{a}$ Reunião Brasileira de A ntropologia, realizada em junho de 2004, em sua conferência sobre antropologia e política de cultura, o presidente do Iphan, o antropólogo A ntônio A ugusto A rantes, provocou o interesse da platéia ao falar sobre os procedimentos de registro dos bens culturais de natureza imaterial. A lém da conferência, fóruns de pesquisa e simpósios trataram o tema "patrimônio" nas mais diversas perspectivas. Isto sinaliza para o fato de que a política de "patrimônio" adquire uma nova dimensão. Calcada na noção antropológica de cultura, desloca-se da aceitação de um produto único, de valor "excepcional", e passa a ser pensada como um processo, um ressignificar-se, um fazer-se a cada modalidade de interação, a cada configuração de posições e a cada contexto histórico. Nessa perspectiva, a categoria patrimônio adquire aquilo que pode-

\footnotetext{
* Mestre em História da Cultura pela PUC-Rio. Doutoranda em Antropologia pelo PPGA/Universidade Federal Fluminense. E-mail: lusimao@ibest.com.br.
}

ríamos chamar de densidade etnográfica. ${ }^{1}$ A demais, não se pode mais separar os termos "patrimônio" e "antropologia", pois o alcance das políticas públicas na área da cultura foi potencializado a partir dessa equação.

Hoje, os agentes do patrimônio vêm negociando com os grupos historicamente marginalizados ações de salvaguarda e de preservação dessas memórias periféricas. São práticas sociais não valorizadas, não reconhecidas como significativas e que, recentemente, passaram a ser incorporadas como repertórios representativos de determinados segmentos da sociedade e que merecem a chancela do Estado brasileiro. Nessa relação, entre o olhar do pesquisador e daquele que está participando diretamente da manifestação e para o qual ela é referência, surge a proposta de registro do Patrimônio Cultural B rasileiro. Os desafios para a posição dos antropólogos nos processos de

1. Segundo José Reginaldo Gonçalves, o uso analítico do termo patrimônio, como categoria de pensamento, permite que se possa explorá-lo do ponto de vista etnográfico $24^{\text {a }}$ RB A /2004. 
identificação e de registro do patrimônio, bem como as ferramentas utilizadas para problematizar o campo, ainda estão sendo configurados. As reflexões aqui apresentadas foram discutidas no fórum de pesquisa intitulado $A$ Pesquisa Antropológica e o Futuro das Populações Com Quem se Trabalha: U ma R eflexão Crítica. ${ }^{2}$ Nesse fórum, tratou-se das questões relacionadas ao patrimônio numa perspectiva etnográfica, que situa, na ética do trabalho de campo, os desafios de produzir conhecimento sobre o "outro" - e para esse outro - , na medida em que as demandas devem ser processadas pelos grupos detentores do saber. A minha comunicação focaliza a experiência de registro da pintura corporal e arte gráfica do grupo Wajäpi do A mapá. Procurei identificar os principais interlocutores, os mediadores e os processos de configuração em rede que possibilitavam ações afirmativas para o grupo. M eu objetivo é retomar as questões apresentadas anteriormente, incorporando ao debate novas categorias de análise e novas experiências de registro.

A política de patrimônio foi oficialmente instituída pelo Decreto-lei n. 25 , de 30 de novembro de 1937, que cria o Serviço de Patrimônio Histórico e A rtístico Nacional (Sphan), órgão executivo da administração pública federal, com características muito peculiares, pois elabora a política, cria o instrumento do tombamento e executa a fiscal ização dos bens salvaguardados. A fundação do Sphan, cuja direção foi entregue ao jornalista e advogado mineiro Rodrigo M elo Franco de A ndrade, esteve vinculada à ação militante de al guns intelectuais, sobretudo mineiros e paulistas, entre os quais destacava-se M ário de A ndrade, um dos mais atuantes do grupo, e que havia elaborado, já em 1936, um anteprojeto de lei voltado para a preservação do patrimônio cultural e histórico nacional.

$\mathrm{N}$ ão obstante o patrimônio ser um campo de estudo atravessado por tensões entre grupos

\footnotetext{
2. Comunicação apresentada na XXIV Reunião Brasileira de Antropologia (ABA), em junho de 2004. A gradeço professora Telma Camargo da Silva e ao professor Hugo B enavides, da Fordhan U niversity, e aos colegas participantes do grupo de trabalho, pelas questões levantadas e sugestões dadas e incorporadas ao tema.
}

de intelectuais que disputam a legitimidade de seu próprio discurso, formulando conceitos, criando políticas, aperfeiçoando instrumentos para proteção e salvaguarda, as narrativas construídas por mais de seis décadas de política preservacionista são constantemente marcadas por discursos predominantemente ideológicose políticos, que enfatizam a iminência da "perda" e da "descaracterização" para justificar a intervenção do Estado.

Podemos identificar dois grandes momentos nas narrativas do patrimônio. 0 primeiro, na gestão de R odrigo M elo Franco, com ênfase no debate sobre o nacionalismo e os marcos fundadores da nação; o segundo, na gestão de A luízio $M$ agal hães, que procurou enfatizar a noção antropológica de cultura, centrada na noção de diversidade cultural. Essa concepção procura integrar o patrimônio histórico edificado à pluralidade das manifestações da cultura popular. $^{3}$

Se na fase dita "áurea" do Sphan, o discurso que predominava era o monumentalista (M alhano, 2002), na fase seguinte, a instituição reviu algumas posições e incorporou a sua política processos sociais até então invisíveis. ${ }^{4}$ Foram os projetos experienciados pelo Centro Nacional de Referências Culturais (CNRC), e direcionados ao artesanato da cerâmica e da tecelagem; ao artesanato de transformação e reciclagem; ao museu ao ar livre de Orleans $(\mathrm{SC})$; à produção de banana-passa na região fluminense; e tantos outros, que procuravam romper com a idéia de identidade hegemônica (Fonseca, 1997, p. 165-166). Os resultados desse entendimento de contextos específicos foram consolidados na Constituição de 1988, cujo texto caracteriza-se por sua pluralidade e seu multiculturalismo.

\footnotetext{
3. A esse respeito ver em GonçALVES, José Reginaldo. A retórica da perda. Os discursos do patrimônio cultural no Brasil. Rio de Janeiro: UFRJ; I phan, 1996.

4. Alguns autores já trataram desse processo de ressignificação porque passou o I phan, a partir de meados da década de 1970. São análises importantes para situar o debate e as distensões do campo. Ver FonseCA, M. C. L. O patrimônio em processo: trajetória da política federal de preservação no Brasil. Rio de Janeiro: Editora UFRJ: Iphan, 1997; GoNÇALVES, J.R. S. A retórica da perda. Os discursos do patrimônio cultural no Brasil. Rio de Janeiro: Editora UFRJ: I phan, 1996.
} 
Em 4 de agosto de 2000, o então presidente da República, Fernando Henrique Cardoso, assinou o D ecreto 3.551, que instituiu o R egistro de Bens Culturais de Natureza Imaterial. 0 mesmo decreto criou o Programa $\mathrm{N}$ acional de Patrimônio Imaterial. 0 programa prevê o inventário das manifestações de caráter tradicional e popular por todo o território brasileiro. Esse novo instrumento é denominado I nventário Nacional de Referências Culturais (INRC), que representa extensos formulários aplicados pelos inventariantes, quando julgam estar diante de uma "referência cultural". Essa noção é fundamental no discurso contemporâneo do patrimônio cultural, e suas origens estão ancoradas na experiência do CNRF.

As perguntas que os agentes envolvidos vêm fazendo, quanto à maneira de se registrar um bem de natureza imaterial - seja um ritual, uma performance, um saber, uma expressão, ou um lugar, são: que instrumento é capaz de sal vaguardar bens de natureza não-tangível, de caráter dinâmico, e intimamente associados a práticas e representações culturais de grupos? 0 registro de um bem em livros especiais do I phan éo suficiente para salvaguardá-Io, ou seja, dar a ele condição de florescimento? O u o registro é apenas uma forma de identificação? Quais seriam os mecanismos capazes de fazer surgir uma atitude articulada entre "instituições públicas e diferentes instâncias das comunidades para o processo de reconhecimento, registro, fomento e preservação dos bens culturais em questão?" (Fonseca, 2004, p. 17).

É de se supor que, pela natureza dos bens inventariados pelas agências de preservação do patrimônio, os procedimentos de registro devem seguir conceitos e metodologias das ciências sociais. N esse sentido, a descrição etnográfica é um gênero privilegiado para a apresentação das interpretações culturais. 0 tema que me proponho a tratar, apesar de seus muitos vieses, apresenta-se como um exercício de reflexão para o fazer etnográfico. Circunscrevo, portanto, minhas preocupações na autoridade do inventariante (antropólogo ou não-antropólogo) e na sua capacidade auto-reflexiva ao aplicar os extensos formulários do INRC. Tais questionamentos parecem-nos bastante oportunos, sobretudo num momento em que há uma demanda pelo saber antropológico nos processos de registro do patrimônio imaterial.

Portanto, e para que se possa refletir sobre os instrumentos de registro elaborados por agentes e agências, faz-se necessário percorrer uma dupla trajetória: primeiro, deve-se problematizar, à luz da teoria antropológica contemporânea, a relação sujeito/objeto do conhecimento, que vai refletir no posicionamento do antropólogo em campo, na sua postura reflexiva diante dos dados coletados, ao questionar as continuidades, os poderes e interesses envolvidos no campo e seus reflexos na escrita etnográfica. N um segundo momento, devem-se investigar os vínculos institucionais e as interlocuções entre antropólogos, agentes e agências, que vão estabelecer os "elos, os recursos e os al iados disponíveis" (L atour, 2000, p. 104) para a flexibilização das fronteiras do patrimônio.

O estado das artes da teoria antropológica

A crítica aos princípios colonialistas significou uma ruptura entre o cânone moderno e 0 pós-moderno. A figura do antropólogo, muitas vezes associada à administração e aos interesses col onialistas, foi duramente criticada, a partir do processo de descolonização. A cusados de produzir conhecimento a favor do status quo, contribuindo pouco ou quase nada para mudanças significativas das realidades estudadas, a comunidade antropológica precisou se separar dos sistemas classificatórios evolucionistas e reinventar seus instrumentais teórico-metodológicos. Não obstante os avanços na teoria antropológica, fica ainda o dissabor de produzir um conhecimento sobre e para o outro. Essa assimetria de posições, encontrada desde a institucionalização da disciplina, e que correu paral elamente aos processos coloniais, lança um desafio ético para o pesquisador.

A o ter claro que o produto da investigação é um texto, e que este é conseqüência de um processo de interação, no qual a síntese, a organização e a interpretação são dadas pelo agente da investigação, pede-se um rigor formal na apresentação dos resultados da pesquisa. G eertz representou um corte epistemológico na teoria antropológica moderna, pois abandonou 
as explicações calcadas em grandes contextos de causa e efeito para optar por analisar os fenômenos sociais com base nas representações e nos sistemas de significações (Geertz, 1997, p. 13). Críticos mais contemporâneos da teoria reconhecem que a "antropologia interpretativa foi a primeira a ver as culturas como um conjunto de textos, focando a inventiva poética que foge a repertórios engessados, num fluir de representações coletivas" (James, 2002, p. 42).

A década de 80 do século $X X$ foi marcada pelo fim das certezas epistemológicas. Em 1986, James Clifford \& George M arcus publicam Writing culture. The poetics and politics of ethnography. Esselivro é uma coleção de nove ensaios, cujo foco recai sobre a construção dos textos etnográficos no contexto de produção da antropologia cultural norte-americana. Virtualmente, quase todos os ensaios analisam criticamente a prática da escrita etnográfica. Essa visão crítica surge da constatação de que todas as representações são, na verdade, construções sociais altamente ideologizadas. Desse modo, os "outros" que aparecem nas etnografias modernas, mais do que "outros" em seus próprios termos, são "outros" nos termos próprios do etnógrafo (Clifford \& M arcus, 1986). Se G eertz discute sobre as estratégias textuais e os jogos retóricos da linguagem que buscam persuadir 0 leitor de que o antropólogo "esteve ali" e foi capaz de traduzir o universo cultural do "nativo", o grupo que se constitui a partir da publicação do Writing Culture visava questionar os "efeitos" sobre as representações da realidade.

Em 0 antropólogo como autor (2002, p. 11-40), G eertz questiona a transparência do texto científico e lança a idéia do relato etnográfico como ficção. Porém, a capacidade de dar sentido às representações dos agentes é garantida pela experiência de campo. A o recusar a idéia de que o texto etnográfico é capaz de repor a realidade vivida no trabal ho de campo, os pósmodernos garantem que a tarefa do antropólogo é tão somente dar voz ao "nativo" e construir 0 texto dentro de uma perspectiva dialogal ou polifônica.

0 primeiro fundamento metodológico dos pós-modernos é o da subordinação do texto etnográfico aos limites estruturais da linguagem. A demais, criticam a retórica construída para invisibilizar o narrador ou enunciador, e lançam dúvidas sobre a representação objetiva. N otase uma tensão permanente entre um saber produzido "objetivamente" e uma crítica à visão naturalizada da representação: 0 gênero da descrição etnográfica deixa de ser "objetivo" para transformar-se em "arte" (Clifford, 1986, p. 4). Mais ainda, questiona-se a pretensão utópica de dar conta do universo pesquisado. $\mathrm{Na}$ concepção desses autores, toda descrição é parcial, o que supõe que não se pode capturar a totalidade a partir de fragmentos experienciados: a realidade surge com o observador; logo, haverá tantas realidades quanto determinados fenômenos forem observados. A intertextualidade é outro ponto levantado e diz respeito aos modos de produção e recepção dos textos que sempre remetem a outros textos, construindo escritos híbridos e imersos na fragmentação.

A despeito de uma pulsão fundada na certeza do jogo das interpretações, essa nova corrente posiciona-se a favor de uma perspectiva fragmentária, híbrida e construcionista da realidade social. A maneira pós-moderna de ol har o mundo fundamenta-se diferentemente do modo em que se baseavam os modernos de outrora, não obstante 0 fato de que há quem afirme que "jamais fomos modernos".

Como escapar de tantas incertezas e trilhar um caminho menos melancólico? Ou, seria melhor dizer, como criar novos paradigmas e não se deixar envolver com ilusões construtivistas ou realistas? Para superar as ambivalências e dicotomias e quebrar com o paradigma da fragmentação, L atour dá-nos outras pistas. Segundo esse autor, "as mesmas questões sobre causas, efeitos, elos e porta-vozes podem ser levantadas em todos os lugares, abrindo assim um campo ilimitado de estudo para a antropologia" (Latour, 2000, p. 335). A ssim, o que parece estar em jogo não são as formas prélógicas ou lógicas que promovem a grande divisão entre "nós" e "eles", "a principal dificuldade ao se mapear o sistema de associações heterogêneas está em não fazer nenhuma suposição adicional sobre sua realidade" (Latour, 2000, p. 336).

Quais seriam as implicações de pensar os aparatos conceituais em rede ou mundo contínuo, abandonando as visões sobre a alteridade, a 
construção ou o real? A s redes expandem-se e contraem-se, no tempo e no espaço, conforme a posição e a legitimidade dos atores.

E sta parece-nos uma perspectiva operativa bastante importante para pensar sobre a figura do porta-voz que, inserido em sua rede de relações, sustenta uma posição representativa. Geralmente representa o consenso, fruto de intensa disputa, no interior das redes ( $L$ atour, 2000, p. 121). Contudo, a controvérsia é constitutiva do papel social que ocupa. Segue-se, daí, tornar-se um bom mediador para amenizar os conflitos. 0 termo mediação associada ao patrimônio adquire, portanto, um significado específico, adjetivado.

Sua posição vai depender de seu poder de argumentação. Quanto mais sua retórica permanece forte, maior é o seu poder de convencimento para agregar val ores, recursos, equipamentos, pessoas e financiamentos ( $L$ atour, 2000, p. 33). Quem não foi pego em sua malha, deve abrir as caixas-pretas do conhecimento para que "os leigos possam dar uma olhada" (L atour, 2000, p. 34).

$\mathrm{Na}$ perspectiva de Bourdieu, a crítica que se faz ao porta-voz é de que ele representa facções, fragmentos de um campo de disputa. Deve-se lembrar que, em sua noção de campo, Bourdieu entende-o como um "universo autônomo, um espaço de jogo, onde se joga um jogo que possui regras próprias; e as pessoas envolvidas nesse jogo possuem, por esse motivo, interesses específicos, interesses que são definidos pela lógica do jogo e não pelos mandantes" (B ourdieu, 1990, p. 200).

Os efeitos simbólicos da linguagem fazem do porta-voz um representante autorizado, posto que 0 "ato de simbolização" representa a possibilidade de o significante identificar-se à coisa significada (B ourdieu, 1990, p. 192). Esse jogo de espelhos, que pode representar a incapacidade de se inserir em determinadas redes e de ser o seu porta-voz, reflete no "conjunto de situações em que alguém fala em nome de alguma coisa a que esse al guém dá existência por meio de seu próprio discurso" (B ourdieu, 1990, p.197), e escamoteia relações de poder. Como exemplo típico de usurpação do sujeito, B ourdieu cita o debate paradigmático da cultura popular, que é transpassado pelo formalismo e pelo academismo, e que constrói iconografias alegóricas que nada correspondem às práticas sociais daqueles grupos (B ourdieu, 1990, p. 199).

Nessa perspectiva, as redes construídas pelo patrimônio pressupõem um crescente número de mediadores, associações, instituições, recursos e aliados disponíveis na tessitura de seus fios. Quando se busca reconhecer todos os atores, impressiona a sutileza com que tramam suas malhas.

\section{A flexibilização das fronteiras do patrimônio}

Em termos analíticos, a noção de patrimônio cultural vem sendo debatida com base nos dispositivos legais que ordenam os discursos e as ações governamentais. Em geral, adotam-se as categorias consagradas internacionalmente. A s concepções elaboradas pela U nesco sobre patrimônio cultural e natural foram firmadas na Convenção de 1972.

A dota-se, nessa convenção, a seguinte definição de patrimônio cul tural:

A rtigo 1

Para fins da presente Convenção serão considerados como patrimônio cultural:

- os monumentos: obras arquitetônicas, de escultura ou de pintura monumentais, elementos ou estruturas de natureza arqueológica, inscrições, cavernas e grupos de elementos, que tenham um valor universal excepcional do ponto de vista da história, da arte ou da ciência;

- os conjuntos: grupos de construções isoladas ou reunidas que, em virtude de sua arquitetura, unidade ou integração na paisagem, tenham um valor universal excepcional do ponto de vista da história, da arte ou da ciência;

- os lugares notáveis: obras do homem ou obras conjugadas do homem e da natureza, bem como as zonas, inclusive lugares arqueológicos, que tenham valor universal excepcional do ponto de vista histórico, estético, etnológico ou antropológico. ${ }^{5}$

5. A Conferência Geral da Organização das Nações Unidas para a Educação, a Ciência e a Cultura, reunida em Paris, adota em 16 de novembro de 1972 a Convenção relativa à Proteção do Patrimônio M undial, Cultural e Natural (apud. LOPES, A na e SANTOS, Aline (Orgs.) Cidadania cultural: legislação. São Luís: Estação Produções, 2003, p. 13-14). 
Q uanto à citação, podemos fazer al gumas observações pertinentes. Primeiro, a noção de patrimônio cultural ainda se encontra bastante naturalizada. A noção de sítio arqueológico, por exemplo, apesar do entendimento de que é um bem construído pelo homem, ainda se integra à paisagem natural. Outro problema é o valor de natureza "excepcional", associado aos bens culturais. A categoria de "excepcionalidade" do bem vem sendo amplamente criticada e há quem proponha "a adoção do critério de representatividade (e não de excepcionalidade, como na Convenção de 1972) na inscrição de bens na Lista criada pela Convenção" (L ondres, 2004, p.12).

A concepção arqueológica de bem opera com duas categorias-chave: a de artefato e de vestígio. Tais categorias adjetivam o bem material, circunscrevendo-o no tempo e caracterizando-o como um documento/monumento. $\mathrm{A}$ produção de conhecimento arqueológico, portanto, não está descolada de uma perspectiva histórica mais ampla. Porém, seus sistemas classificatórios tendem a se distanciar de uma perspectiva antropológica mais crítica. $\mathrm{Na}$ verdade, e no que tange à produção do conhecimento antropológico, há toda uma preocupação, desde finais de século XIX, de separar a noção de etnologia da noção de arqueologia. Essa distinção, nascida dentro dos museus, fez com que houvesse uma descontinuidade de perspectiva teórico-metodológica no domínio dessas disciplinas.

No Brasil, a primeira notícia de flexibilização das fronteiras do patrimônio vem através da L ei 3.924, de 26 de junho de 1961, que dispõe sobre os monumentos arqueológicos e préhistóricos. A legislação de arqueologia de 1961, no que se refere aos desafios e problemas encontrados pelos agentes e agências que atuavam no campo do patrimônio, significou um avanço de concepção teórica e de instrumentais técnicos para lidar com esse novo tipo de bem. Com que interesse e como poderia ser feito 0 reconhecimento do bem a ser preservado, era assunto na pauta de discussão dos agentes e das agências de preservação.

A questão da excepcional idade na arqueologia é muito complicada, porque a mesma legislação garante importância e valor iguais aos bens de natureza arqueológica. Trata-se de testemunhos de grupos que ocuparam determinado território em determinado período préhistórico. Portanto, todos os sítios têm a mesma importância, porque se opera numa perspectiva de contexto de ocupação que deixa um registro pictórico ou um artefato humano.

A legislação de 1961 é totalmente focada na pré-história e surge em virtude de uma demanda muito específica: a destruição em massa dos sambaquis, que são os sítios arqueológicos pré-históricos e que correspondem aos acúmul os artificiais de conchas. É curioso notar que esse movimento preservacionista dos sambaquis não parte do órgão de preservação, mas sim de instituições de ensino e pesquisa do país. ${ }^{6}$

Na verdade, o Decreto-L ei no 25, de 1937, já previa a arqueologia dentro da perspectiva de preservação. No entanto, o instrumento que - Sphan dispunha para proteção e acautelamento do bem arqueológico era o tombamento. A demais, a perspectiva de tombamento de sítio impede justamente a produção de conhecimento. Sea perspectiva de tombar pressupõe imobilizar e não poder mexer mais, porque subentende cristalizar num dado momento, como produzir dados e conhecimento sobre determinado sítio arqueológico? 0 instrumento tombamento é indicado para os bens chamados de "pedra e cal", mas os sítios são espaços que precisam ser destruídos para produzir conhecimento sobre eles. Surge, então, um impasse.

A lei de arqueologia foi feita para garantir a produção do conhecimento, tanto que prevêa identificação e o registro dos sítios. Também prevê, como método de escavação, a manutenção do "bloco testemunho", que significa deixar intacta uma parte do sítio para que outras equipes, no futuro, com outras técnicas, outras perspectivas e outras questões, possam produzir novos conhecimentos. Por exemplo, num sambaqui, pode-se estudar seu padrão de assentamento, ou seu padrão de enterramento, ou, ainda, querer saber sobre os vestígios da cultura material. Tudo isso vai depender do ol har e das perguntas da equipe de pesquisadores.

6. O M useu Nacional do Rio de J aneiro e o M useu de Etnologia da USP foram os articuladores, em conjunto com o Sphan, na elaboração da legislação. 
0 conceito de patrimônio cultural e natural, na Convenção de 1972, já previa a discussão sobre bens arqueológicos. Essa preocupação, na verdade, já havia sido contemplada na Carta de N ova Delhi de 1956, quando se debateram sobre questões específicas do patrimônio arqueológico. Há uma continuidade histórica e de evolução conceitual que autoriza a inclusão de novos elementos nas políticas de preservação. A mpliam-se, portanto, os debates, os mediadores, as instituições que lidam com essa categoria. $\mathrm{Na}$ seção seguinte, debateremos sobre as novas construções do patrimônio.

A construção de uma noção: o patrimônio imaterial

Desde então, as convenções, recomendações e resoluções internacionais relativas aos bens culturais foram incorporando novos elementos. Em sua 25a Conferência Geral, realizada em 15 de novembro de 1989, em Paris, a Unesco aprovou a Recomendação sobre a Salvaguarda da Cultura Tradicional e Popular. Finalmente, na sua $32^{\text {a }}$ Conferência Geral, adotou a Convenção para a Salvaguarda do Patrimônio Cultural Intangível, contendo a seguinte definição de "Patrimônio I material":

[...] práticas, representações, expressões, conhecimentos e habilidades - assim como os instrumentos, objetos, artefatos e espaços culturais associados a isso - que comunidades, grupos e, em alguns casos, indivíduos reconhecem como parte de seu patrimônio cultural. Este patrimônio cultural intangível, transmitido de geração a geração, é constantemente recriado por comuni dades e grupos em resposta ao seu meio ambiente, sua interação com a natureza e sua história, e fornece-Ihes um senso de identidade e continuidade, assim promovendo respeito pel a diversidade cultural e pela criatividade humana. (2003)

O B rasil destaca-se no cenário internacional não só por sua diversidade cul tural, mas também por ter desenvolvido os instrumentos legais para mobilizar o Estado a reconhecer e registrar as manifestações culturais de caráter tradicional e popular. Importante observar que tais questões já haviam sido formuladas por pensadores como
M ário de A ndrade, na década de 30 do século $X X$, e A loísio $M$ agal hães, em meados da década de 70 , com a experiência do Centro $\mathrm{N}$ acional de Referências Culturais (CNRC).

Foram as suas novas configurações, nas décadas de 1970 e 1980, que flexibilizaram as rígidas frontei ras do patrimônio, adquirindo uma perspectiva inclusiva de grupos, tanto que 0 nosso sistema jurídico tende a reconhecer a pluralidade da composição da sociedade brasileira. A Constituição de 1988, em seus artigos 215 e 216, reconhece os direitos cul turais como constitutivos da cidadania e os bens de natureza material e imaterial como patrimônio cultural brasileiro. Nesse sentido, a assinatura do Decreto no 3.551, que "institui o R egistro dos $B$ ens Culturais de natureza imaterial que constituem Patrimônio Cultural brasileiro", regulamenta os artigos "Da Cultura" da Constituição.

Todos os indivíduos/grupos interessados em registrar determinado saber, ou manifestação, ou técnica e habilidade, ou formas de expressão devem encaminhar suas propostas de registro, "acompanhadas da documentação técnica,... ao Presidente do Iphan, que as submeterá ao Conselho Consultivo do Patrimônio Cultural" (artigo $3^{\circ}$ ). Para tal, o I phan vem desenvolvendo uma metodologia específica, o INRC, que está sendo aplicado e testado.

Etimologicamente, a palavra inventário deriva do latim jurídico inventarium e pode significar levantamento individuado e completo de bens e valores. Por definição, significa rol completo, e a sua primeira característica é a exaustividade (INRC, M anual de A plicação, p. 27-28). 0 inventário permite aos pesquisadores identificar aquilo que é referência para o grupo. Sua função é produzir conhecimento e ser um instrumento de sensibilização, para que possa indicar os interesses por determinadas referências culturais e sustentar uma política consistente de salvaguarda.

\section{Os instrumentos inventário e registro e seus desafios}

0 inventário é peça fundamental para que se possa instruir o registro do bem de natureza imaterial, caso se siga a metodologia proposta 
pelo I phan. Não há obrigatoriedade em seguila, tanto que o registro da arte K usiwa seguiu 0 formulário da Unesco. M as, por enquanto, 0 K usiwa foi uma exceção e as experiências com a metodologia do INRC são as mais freqüentes.

N essa perspectiva, o que constitui o Registro do Patrimônio Cultural Brasileiro? O que diferencia inventário de registro? Q uando se dá essa passagem? Quais são os equilíbrios de forças que permitem essa passagem? Como fica o bem registrado daqui a dez anos? Estas e outras questões estão sendo formuladas e postas à prova por uma perspectiva inclusiva de grupos. $M$ inha hipótese é que inventário e registro são instrumentos poderosíssimos de pressão política e que todo o esforço de compreensão está em reconhecer os principais agentes da ação política.

Vamos comparar duas experiências institucionais: a primeira, proposta pelo $M$ useu do Índio sobre o registro da pintura corporal Wajäpi, primeiro patrimônio cultural brasileiro cuja metodologia seguiu o dossiê de candidatura à Segunda Proclamação das Obras-Primas do Patrimônio Oral e Imaterial da Humanidade U nesco. A segunda, sobre o projeto Cel ebração e Saberes da Cultura Popular, do Centro Nacional de Folclore e Cultura Popular, cuja metodologia procurou adequar os projetos de pesquisa desenvolvidos pelo centro às extensas fichas que compõem o inventário e aplicá-lo de maneira crítica. Seguem-se daí as indagações sobre as maneiras de aperfeiçoar os mecanismos de registro e demais políticas de salvaguarda do patrimônio tradicional e popular.

0 processo de registro da arte $K$ usiwa foi apreciado e aprovado na $38^{a}$ reunião do Consel ho Consultivo do Patrimônio Cultural, em 11 de dezembro de 2002. Para efeito de anál ise, fomos buscar o agregado de informações e documentos sobre o processo no M useu do Índio/ Funai. A s questões que procuramos responder referem-se às políticas públicas vol tadas para a cultura, bem como focar nas trajetórias institucionais e nas parcerias que configuram processos de construção em rede. São as mediações e parcerias entre agentes e agências, nacionais e internacionais, entre agências e universidades, entre Estado e sociedade civil que configuram as novas redes do patrimônio.
Tomando-o como termo de comparação com outros inventários e pedidos de registro, procurou-se responder a seguinte questão: por que registrar a arte $\mathrm{K}$ usiwa? Todo o nosso esforço foi no sentido de compreender o contexto de produção desse registro. Desse lugar, portanto, surgiram novos questionamentos: quais foram as forças políticas que viabilizaram a candidatura da expressão gráfica K usiwa a Patrimônio Cultural Brasileiro e a Patrimônio Oral e Imaterial da Humanidade? Por que utilizar uma outra metodologia de registro?

Começando pela última questão, sabe-se que as duas candidaturas foram encaminhadas na mesma época. Havia todo um esforço por parte do governo brasileiro em formalizar o instrumento do registro, previsto na legislação de 2000, e que ainda não havia saído do papel. Portanto, o encaminhamento para registro das pinturas corporais Wajäpi deve ser compreendido dentro de um contexto mais amplo.

A lém disso, havia uma conjunção de fatores que conspirava a favor da candidatura: um trabal ho de pesquisa de décadas com o respaldo de instituição universitária; o envolvimento da comunidade Wajäpi; o apoio dos governos estadual e federal em programas para formação de educadores índios e projetos de autosustentabilidade.

Por fim, o Museu do Índio acabava de inaugurar a exposição sobre os Wajäpi e de editar o catálogo Kusiwa: pintura corporal e arte gráfica Wajäpi, com parte do repertório de desenhos. ${ }^{7}$

\footnotetext{
7. A gradeço a entrevista concedida pelo diretor do $\mathrm{M}$ useu do Índio, 0 antropólogo José Carlos Levinho, da qual transcrevo abaixo o seguinte trecho: "Sobre a trajetória do M useu do Índio [...] nós desenvolvemos um trabal ho bastante consistente na área de identificação do acervo do museu. Então, nós construímos uma massa de dados e desenvolvemos uma política que é extremamente complexa, difícil e lenta de realizar. 0 inventário do acervo do Museu do Índio é complexo pelo instrumento [...] Nós temos um acervo muito bem organizado em todos os níveis, e com uma estrutura de informação sobre ele muito grande. Então, em termos de inventário, o museu deu conta de praticamente todo 0 acervo. Dentro disso, existe uma infinidade de problemas. Há toda uma dinâmica aí complexíssima sobre todos os aspectos do que é construir, sistematizar informações sobre um acervo e disponibilizá-las na Internet 0 banco de dados é uma conseqüência da organização desse acervo [...]. 0 museu iniciou uma estreita relação com o M inistério da Cultura e passou a desenvolver trabalhos em parceria. Foi dentro desse contexto que eu fui chamado para participar
} 
Q uanto ao dossiê de candidatura, e fazendo uma análise de seu conteúdo, toda a primeira parte pretende ser descritiva da expressão cultural. A descrição etnográfica do bem focou no significado simbólico, na descrição técnica do repertório codificado e nos padrões da arte Kusiwa. Seguem-se daí os argumentos para a candidatura, que se pauta no discurso da diversidade e do respeito às diferenças e no da inexorável perda, caso os poderes públicos e a sociedade civil (organizada em associações) não se responsabilizem por constituir políticas de salvaguarda, de valorização e de preservação das culturas humanas (G allois, 2002).

Porém, é a partir da segunda parte que as configurações em rede são acionadas. O bservase que são propostos mecanismos institucionais para a gestão e implementação de uma política de proteção ao patrimônio oral e imaterial dos Wajäpi, assim como os principais el ementos de um plano de ação a ser desenvolvido por essa comunidade, através de associação indígena por ela criada - o Conselho das A Ideias Wajäpi/ A pina, em colaboração com as instituições parceiras: o M useu do Índio/Funai, o Núcleo de História Indígena e do Indigenismo/N HII-USP e o Núcleo de Educação Indígena do Estado do A mapá/NEI (Gallois, 2002).

Identificados os interlocutores, parte-se para as principais linhas de ação propostas no dossiê: primeiramente, busca-se implementar uma campanha de difusão e revitalização dirigidas aos múl tiplos agentes que atuam junto à comunidade. Um segundo componente é a formação de educadores e pesquisadores indígenas para que possam realizar levantamentos sistemáticos - a elaboração de um inventário participativo - e garantir que o sistema referencial esteja em acordo com as demandas do grupo. Por fim, propõe-se a implantação de um centro de referência da cultura dos Wajäpi do A mapá, que serviria de guardião dos produtos do inventário e do registro participativo. Todas essas medidas, no entanto, pressupõem um acompanhamento sistemático das instituições

do grupo de trabalho de regulamentação do Decreto 3.551. $\mathrm{N}$ ão havia muita discussão sobre índios, inclusive, a questão no decreto de línguas indígenas não está presente, o que é um absurdo. Uma política de patrimônio imaterial que não contempla a diversidade lingüística no Brasil [...]". parceiras, tanto no que se refere à gestão, quanto às ações.

A outra experiência de inventário segue a metodologia elaborada pelo I phan. Em 2000, 0 Centro Nacional de Folclore e Cultura Popular (CNFCP) elaborou o Projeto Celebrações e Saberes da Cultura Popular, com o objetivo de testar a aplicabilidade do INRC. Dividido em três etapas, o projeto já inventariou alguns tipos de bens: as violas de cocho de $M$ ato Grosso e $M$ ato Grosso do Sul; o jongo da Região Sudeste; a cerâmica tradicional de Candeal, em M inas Gerais, e de Rio R eal, na B ahia; o complexo do boi em São Luís; o acarajé em Salvador e as farinhas no Pará. ${ }^{8}$

Em cinqüenta anos de atuação e formulação de políticas públicas no campo das cul turas populares, o CNFCP constitui-se como herdeiro direto do Instituto $\mathrm{N}$ acional de Folclore. Esse campo foi estruturado na década de 40 do século $X X$, com a institucional ização da Campanha de D efesa do Folclore B rasileiro. E m 1947, viviase um espírito de pós-guerra, e as organizações internacionais de cultura respondiam às demandas de salvaguarda das culturas, com toda a sua riqueza e diversidade, informando que este era o nosso "bem" maior da humanidade. 0 B rasil respondeu a essa demanda com a criação da Comissão Nacional de Folclore, vinculada ao Instituto $B$ rasileiro de Educação, Ciência e Cultura (IBECC). ${ }^{9}$

Essa rede espraiou-se em Comissões Regionais, cuja capilaridade e atuação política local ficou enfraquecida e marginalizada nos anos 1970 e 1980, quando foram criados 0 Centro Nacional de Referência Cultural e o Instituto Nacional de Folclore. Essa mudança assinal ou uma ruptura entre o conhecimento

\footnotetext{
8. O Centro Nacional de Folclore e Cultura Popular elaborou um documento, relatando a experiência com o inventário. Ver LONDRES, Cecília et. al. Celebrações e saberes da cultura popular: pesquisa, inventário, crítica, perspectiva. In: Série Encontros e Estudos n. 5. Rio de Janeiro: Funarte, Iphan, CNFCP, 2004, 96 p.

9. 0 Instituto Brasileiro de Educação, Ciência e Cultura está ligado ao Itamaraty. A comissão congregava uma camada de intelectuais, que se dizia comprometida com os segmentos sociais identificados como das classes populares. A atuação política restringia-se a registrar e, portanto, não deixar "morrer" essa cultura "autêntica". O Instituto Nacional de Folclore (INF), na década de 1980, rompe com as proposições folcloristas.
} 
antropológico e o folclorista e apontou para deslocamentos na esfera institucional, que envolvia perda de poder e de controle administrativo por parte dos folcl oristas das instituições criadas pelo M ovimento Folclorista, vivência de uma situação periférica nas instituições de ensino e de pesquisa. Surgiram também profundos questionamentos de caráter epistemológico sobre os métodos e conceitos empregados pelos folcloristas. A teoria antropológica e o método etnográfico constituíram-se, assim, como os mais autorizados para o estudo do campo das culturas populares, ou do folclore e das culturas populares.

Essa trajetória institucional referendou a participação do Centro Nacional de Folclore e Cultura Popular em todas as etapas de formulação da política do patrimônio imaterial. Desde 1998, em diálogo direto com o I phan, esteve presente, junto com o M useu do Índio, na formulação do Programa Nacional de Patrimônio I material, também previsto no Decreto de 2000.

A té o momento, o centro possui o maior número de "bens" de natureza "imaterial" inventariados e, por ter uma amplitude nacional, buscou elementos "referenciais" tradicionalmente associados às camadas das culturas populares. 0 barro, o boi, o feijão, as violas e os batuques e as farinhas foram inventariados em contextos e processos socioculturais singulares.

As experiências de inventário feitas pelo CNFCP foram significativas para se avançar em algumas questões, uma vez testadas pelo instrumental teórico-metodológico da antropologia, numa perspectiva inclusiva da diversidade cultural. No entanto, a tensão que se observa está no escopo da análise. Por ser necessária a criação de um banco de dados, "os inventários de identificação têm-se constituído no instrumental técnico, possibilitando a sel eção e o registro de novos valores para preservação, assim como a reflexão sobre novas al ternativas para o cumprimento das competências e deveres da instituição" (M otta \& Silva 1998, p.12).

O Inventário $\mathrm{N}$ acional de Referências Culturais relativo às celebrações, formas de expressão, ofícios e modos de fazer, edificações e lugares tem como objetivo a identificação de bens que sirvam de referência à memória e à identidade de grupos sociais (Relatório do I phan,
2001/2002 - Inventários). N o entanto, o IN RC não é tão-somente um instrumento de identificação, pois seu uso deverá provocar efeitos políticos.

Em palestra realizada no Laboratório de Educação Patrimonial (Laboep/UFF), em 30 de abril de 2004, a coordenadora do Projeto Celebrações e Saberes da Cultura Popular do CNFCP, a antropóloga Letícia Vianna, fez algumas declarações que acreditamos ser importante para o debate.

$M$ as no caso de um boi, um jongo, uma viola de cocho, que muda o jeito de fazer cada [...] canto é um canto, o jongo aqui é uma coisa, 0 jongo ali é outra coisa. Cada bem é um bem. Então ele [o inventário] tem que ser mexido. Em cada inventário desse, a gente operou de uma maneira. E de uma maneira bastante livre. Tinham lugares que existiam perguntas que não cabiam, tinham outras perguntas que tinham que ser feitas e não eram pressupostas aqui. Aí a gente inventou uns quadrinhos e fez um roteirinho, um controle da experiência [...].

Os inventariantes do centro, ao se familiarizarem com o instrumento "inventário", procuravam descrever os "bens culturais em seus contextos correntes e em relação aos sistemas simbólico em que estão inseridos, conforme as referências indicadas pelos informantes" (Vianna, 2004, p. 17). Portanto, operar com as categorias nativas, como referências culturais locais, significa respeitar os processos internos do grupo, suas tensões, suas noções de tempo e espaço, que em muito se diferenciam das representações de quem registra. A lém disso, categorias naturalizadas como sítio e localidade, presentes no formulário do inventário, são relativizadas, porque seu significado pode variar em escala e natureza (Carvalho et al., 2004, p. 29).

0 processo de inventário e registro deve ser 0 mais elástico possível para abarcar a diversidade ea pluralidade culturais. Isso implica envolver todos os agentes que atribuem valor a determinado bem. Para tal, faz-se necessário restituir a rede de relações da qual fazem parte. U m dos pontos centrais é a tentativa dos órgãos de preservação em consol idar uma metodologia de inventário com base na noção de ' referência 
cultural' . A pesar de atentos ao perigo das tipificações e atomizações, a questão que se impõe é de quem atribui valor a quê. A ampliação das fronteiras do patrimônio pressupõe traçar trajetórias, reconfigurar o campo, estabelecer determinada noção de situação. Deve-se compreendê-la na relação. Para além das configurações políticas, pressupõe sentidos os mais variados, que devem ser aclarados e postos em diálogo.

Se não houver motivação, se as pessoas não absorverem, não entenderem e transmitirem aquilo, viverem aquilo dia-a-dia como um patrimônio, aí que a noção de referência é importantíssima só é possível se manter um patrimônio imaterial enquanto ele for referência vivida, cotidianamente. Esse é nosso entendimento, e por isso que a gente pensa enquanto política de Estado não basta o registro, pois registro você reificou e está lá. U m dia aquilo foi reconhecido como patrimônio. 0 que éinteresse de política publica, no nosso entender, é a ação afirmativa ali na comunidade. ${ }^{10}$

Implicada no registro do Patrimônio Imaterial está a garantia dos direitos de autor, que, no caso dos Wajäpi, foi reconhecido como expressão de um grupo, e caso for utilizado, terão de ser revertidos os benefícios daquele uso à comunidade. Também devem-se criar condições para que sua transmissão seja facilitada por políticas afirmativas. N esse contexto, e como bem sinaliza Carvalho (2004, p. 85-94), é necessário restituir a dignidade e 0 respeito de transmitir o seu legado às gerações futuras.

Abstract: This communication intends to be reflexive
about the boundaries of the recent instruments for the
protection and the preservation of the immaterial heritage.
From the presentation of the problem - about the
anthropological' method - we are going to compare two
institutional experiences. The first one, proposed by the
Indian Museum, about the registration of book painting

10. Palestra ministrada pela antropóloga Letícia Viana, coordenadora do Programa Celebrações e Saberes da Cultura Popular, do Centro Nacional de Folclore e Cultura Popular/ I phan, na Universidade Federal Fluminense, na Faculdade de Educação, dentro das atividades programadas pelo Laboratório de Educação Patrimonial (Laboep), em 30 de abril de 2004. of the W ajäpi Indians of Amapá (Brazil). The second, about the Project Celebrations and Knowledge of Popular Cultural of National Center of Folklore and Popular culture. From these points emerge the questions about the manner of improving the registration mechanisms and other public policies of safeguard.

K ey-words: immaterial heritage, inventory and register, anthropology.

\section{Referências}

ABREU, R.; CHAGAS. M. M emória e patrimônio ensaios contemporâneos. Rio de Janeiro: Editora DP\& A, Faperj, 2003.

BOURDIEU, Pierre. Coisas ditas. São Paulo: Editora B rasiliense, 1990.

CARVA LHO, Luciana, R eflexões sobre a experiência de aplicação dos instrumentos do Inventário Nacional de Referências Culturais. In: FONSECA, M. C. L. et al. Celebrações e saberes da cultura popular: pesquisa, inventário, critica, perspectiva. Rio deJ aneiro: Funarte, I phan, CNFCP, 2004.

CLIFFORD, James; MARCUS, George (Orgs.). Writing culture. The poetics and politics of ethnography.Berkeley: University of California Press, 1986.

CLIFFORD, James. A experiência etnográfica. A ntropologia e literatura no século XX. Rio de J aneiro: Editora UFRJ , 2002.

CSORDA S, T. J. Body meaning healing. N ew York: Palgrave M acmillan, 2002.

FA RIA , L uís de Castro. Antropologia. Espetáculo e excelência. Rio de J aneiro: Editora UFRJ / Tempo Brasileiro, 1993.

. Nacionalismo, nacionalismos - dualidade e polimorfia. In: CHUVA, Márcia (Org.). A invenção do patrimônio. Rio de J aneiro: I phan, 1985.

FONSECA, M.C. L. 0 patrimônio em processo: trajetória da política federal de preservação no B rasil. Rio de J aneiro: Editora UFRJ/Iphan, 1997.

FONSECA, M . C. L. et. al. Celebrações e saberes da cultura popular: pesquisa, inventário, crítica, perspectiva. Rio de J aneiro: Funarte, I phan, CNFCP, 2004. [Série Encontros e Estudos, n. 5].

GA LLOIS, DominiqueTilkin. Boletim do M useu do Índio. D ocumentação n. 9. Rio de J aneiro: M useu do Índio, outubro de 2002.

GEERTZ, Clifford. Obras e vidas. 0 antropólogo como autor. Rio de J aneiro: Editora U FRJ , 2002.

. 0 saber local: novos ensaios em antropologia interpretativa. Petrópolis, Rio de J aneiro: Vozes, 1997. 
GOMES, Ângela de Castro e Neder, Gizlene. A ntropol ogia no B rasil: trajetória intelectual do prof. L uís de Castro Faria (entrevista com o professor L uís de Castro Faria). Tempo, Rio de J aneiro, UFF, v. 2, n. 4, dez. de 1997.

GONÇALVES, J.R. S. A retórica da perda. Os discursos do patrimônio cultural no Brasil. Rio de Janeiro: Editora UFRJ; I Iphan, 1996.

INGOLD, T. The perception of the environment: essays in livelihood, dwelling and skill. London: R outl edge, 2000.

LATOUR, B runo. Ciência em ação. Como seguir cientistas e engenheiros sociedade afora. São Paulo: Editora U nesp, 2000.

LOPES, A na; SANTOS, Aline (Org.). Cidadania cultural: legislação. São Luís: Estação Produções, 2003, p. 13-14.
LONDRES, Cecília. Os inventários nas políticas de patrimônio imaterial. In: LONDRES, Cecília et al. Celebrações e saberes da cultura popular: pesquisa, inventário, crítica, perspectiva. Rio de J aneiro: Funarte; I phan; CNFCP, 2004, p. 12.

MALHANO, M.E. S. M. Da materialização à legitimação do passado: a monumentalidade como metáfora do Estado - 1920-1945. Rio de Janeiro: Editora L ucerna; Faperj, 2002.

VIA N NA, Letícia. Patrimônio imaterial: legislação e inventários culturais. In: FON SECA, M . C. L. et al. Celebrações e saberes da cultura popular: pesquisa, inventário, crítica, perspectiva. Rio de J aneiro: Funarte; I phan; CN FCP, 2004.

Recebido em agosto de 2004 A provado em novembro de 2004 